\title{
FAKTOR-FAKTOR YANG MEMPENGARUHI KEPATUHAN WAJIB PAJAK PADA KKP PRATAMA MAJALAYA
}

\section{FACTORS INFLUENCING COMPLIANCE OF TAXPAYER AT KKP PRATAMA MAJALAYA}

\author{
A. Lasmana, D.A. WIRYANTI \\ Program Studi AkuntansiFakultas Ekonomi Universitas Djuanda Bogor \\ Jl.Tol Ciawi No.1, Kotak Pos 35, Kode Pos 16720, Telp./Fax:0251.8245155 \\ E-mail: andy.lasmana@unida.ac.id, dea.azmi@unida.ac.id
}

\begin{abstract}
This research was intended to analyze the effect of sunset policy, tax amnesty, and good governance on taxpayer compliance in Majalaya primary tax office. The population in this study are all registered taxpayer (corporate and individual taxpayer) in Majalaya primary tax office. The number of samples in this study amounted to 110 respondents. Sampling was done using probability sampling methods. Method of data analysis used in this research was by using validity test, reliability test, classic assumption test, multiple regression analysis, the coefficient of correlation, the coefficient of determination ( $R^{2}$ test), F-test, and t-test. Based on researches results, it can be concluded that simultaneously sunset policy, tax amnesty and good governance have an effect on taxpayer compliance. While partially, sunset policy and tax amnesty hasn't effect on taxpayer compliance, different from good governance which have positive and significant impact to taxpayer compliance.
\end{abstract}

Keywords : sunset policy, tax amnesty, good governance, dan tax compliance

\begin{abstract}
ABSTRAK
Penelitian ini bertujuan untuk mengetahui pengaruh sunset policy, tax amnesty, dan good governance terhadap kepatuhan wajib pajak pada KPP Pratama Majalaya. Populasi dalam penelitian ini adalah seluruh Wajib Pajak (badan dan perorangan) yang terdaftar di KPP Pratama Majalaya. Jumlah sampel dalam penelitian ini berjumlah 110 responden. Pengambilan sampel penelitian menggunakan metode probability sampling. Metode analisis data yang digunakan dalam penelitian ini menggunakan uji validitas, uji reliabilitas, uji asumsi klasik, analisis regresi berganda, koefisien korelasi, koefisien determinasi $\left(\mathrm{R}^{2}\right)$, uji F dan uji t. Berdasarkan hasil penelitian, dapat disimpulkan secara simultan, variabel sunset policy, tax amnesty dan good governance berpengaruh terhadap kepatuhan wajib pajak. Sedangkan secara parsial, sunset policy dan tax amnesty tidak berpengaruh terhadap kepatuhan wajib pajak berbeda dengan variabel good governance yang berpengaruh secara positif dan signifikan terhadap kepatuhan wajib pajak.
\end{abstract}

Kata Kunci : sunset policy, tax amnesty, good governance, dan kepatuhan wajib pajak. 


\section{PENDAHULUAN}

Tren perlambatan pertumbuhan ekonomi nasional Indonesia dalam beberapa tahun terakhir terlihat pada kuartal pertama di tahun 2016 yang hanya mencapai angka 4,92\% dimana angka ini berada di bawah target dari Bank Indonesia sebesar 5\%. Fenomena perlambatan ini berdampak terhadap tidak tercapainya target penerimaan negara salah satunya dari sektor pajak yang tergambar oleh rendahnya tax ratio terhadap PDB Indonesia

Tabel 1: Data Tingkat Kepatuhan WP di Indonesia (2010-2015)

\begin{tabular}{ccccc}
\hline Thn & $\begin{array}{c}\text { Tk. } \\
\text { Kepatuhan (\%) }\end{array}$ & $\begin{array}{c}\text { WP Tidak } \\
\text { Menyampaikan SPT }\end{array}$ & $\begin{array}{c}\text { WP Wajib } \\
\text { Menyampaikan SPT }\end{array}$ & $\begin{array}{c}\text { Total WP yang } \\
\text { Terdaftar }\end{array}$ \\
\hline 2015 & 60,42 & 10.972 .529 & 18.159 .840 & 30.044 .103 \\
2014 & 59,12 & 10.852 .304 & 18.357 .833 & 27.379 .256 \\
2013 & 56,21 & 9.966 .834 & 17.371 .736 & 24.347 .763 \\
2012 & 52,31 & 9.237 .948 & 17.659 .278 & 22.030 .583 \\
2011 & 46,23 & 8.180 .963 & 17.694 .317 & 18.640 .757 \\
\hline
\end{tabular}

Sumber: Ditjen Pajak, data diolah (2017)

Fenomena rendahnya kepatuhan pajak pun terjadi di Kabupaten Bandung, salah satunya di KPP Pratama Majalaya. Hal ini

Tabel 2: Data Tingkat Kepatuhan WP pada KPP PRATAMA MAJALAYA 2013-2015

\begin{tabular}{cccc}
\hline Tahun & $\begin{array}{c}\text { Jumlah Wajib Pajak Terdaftar } \\
\text { Wajib SPT }\end{array}$ & $\begin{array}{c}\text { Jumlah WP yang } \\
\text { Menyampaikan SPT }\end{array}$ & Kepatuhan (\%) \\
\hline 2013 & 118.689 & 37.859 & $31,90 \%$ \\
2014 & 119.213 & 39.116 & $32,81 \%$ \\
2015 & 122.912 & 32.637 & $26,55 \%$ \\
\hline
\end{tabular}

Sumber: KPP Pratama Majalaya, data diolah (2017)

Dalam upaya meningkatkan kepatuhan

wajib pajak, terdapat dua pendekatan yang dilakukan pemerintah, yakni soft approach dan hard approach. Hard approach diimplementasikan melalui pemberian sanksi atau hukuman atas pelanggaran pajak sebagaimana diatur dalam Undang-Undang Nomor 28 tahun 2007 tentang Ketentuan Umum dan Tata Cara Perpajakan. Sedangkan soft approach dilakukan dengan memberikan keringanan atas pelanggaran pajak yang diimplementasikan melalui beberapa kebijakan, diantaranya: Sunset Policy dan Tax Amnesty.

Sunset Policy diberlakukan pada tanggal 1 Mei 2015 berdasarkan Peraturan Menteri Keuangan Nomor: 91/PMK.03/2015 sedangkan Tax Amnesty diterbitkan pada tanggal 1 Juli 2016 berdasarkan UndangUndang Nomor 11 tahun 2016 tentang Pengampunan Pajak. pada tahun 2010-2015 yang berada di bawah tax ratio negara lain di dunia.

Menurut wakil menteri keuangan RI, Prof. Mardiasmo, rendahnya tax ratio Indonesia antara lain dipicu oleh rendahnya tingkat kepatuhan wajib pajak dan terbatasnya kapasitas administrasi perpajakan.

Rendahnya tingkat kepatuhan pajak di negara Indonesia tercermin dalam data tingkat kepatuhan WP pada tahun 2011-2015 dalam Tabel 1 berikut:

ditunjukkan dengan data dalam Tabel 2 berikut. 
yang diterapkan dalam penelitian ini. Data primer yang digunakan untuk pengujian diperoleh melalui instrumen penelitian berupa kuesioner yang disebarkan kepada responden dan diolah serta diuji dengan menggunakan software Statistical Product and Service Solution (SPSS) 20.0 for windows.

\section{Variabel Penelitian}

Sugiyono (2016:39), Variabel independen, variabel ini sering disebut sebagai stimulus, predictor, antecedent, yaitu sunset policy, tax amnesty, dan good governance.

1. Variabel $\mathrm{X}_{1}$ yaitu sunset policy. Pengukuran dilakukan melalui 4 butir pertanyaan yang merupakan pengembangan dari Peraturan Menteri Keuangan Nomor:91/PMK.03/2015.

2. Variabel $\mathrm{X}_{2}$ yaitu tax amnesty. Pengukuran dilakukan menggunakan 5 item pertanyaan (bersumber dari UU RI Nomor 11 Tahun 2016).

3. Variabel $\mathrm{X}_{3}$ yaitu good governance. Pengukuran dilakukan menggunakan 12 pertanyaan yang diadopsi dari penelitian Gunadi (2013).

Sugiyono (2016:39), Variabel dependen sering disebut sebagai variabel output, kriteria, konsekuen, yaitu kepatuhan wajib pajak. Pengukuran menggunakan 10 butir pertanyaan yang diadopsi dari penelitian Permatasari (2016).

\section{Populasi, Sampel dan Teknik Pengambilan Sampel}

Populasi dalam penelitian ini adalah WP terdaftar di KPP Pratama Majalaya tahun 2016 yang berjumlah sebanyak 122.912 orang.

Dengan menggunakan teknik probability sampling melalui rumus slovin diperoleh jumlah sampel sebanyak 99,92 yang dibulatkan menjadi 100 responden.

Berikut ini adalah formula rumus slovin.

Keterangan:

$$
\mathrm{n}=\frac{N}{1+N e^{2}}
$$

$\mathrm{n}=$ ukuran sampel

$\mathrm{N}=$ ukuran populasi

$\mathrm{e}=$ presentase kelonggaran ketidakpastian dengan tingkat kesalahan $10 \%$

\section{HASIL DAN PEMBAHASAN \\ Deskripsi Karakteristik Responden}

Data demografi responden yang diperoleh dari kuesioner penelitian seperti tabel dibawah ini :

Tabel 3. Data Demografis Responden 


\begin{tabular}{|c|c|c|c|}
\hline No. & Keterangan & Total & Presentase \\
\hline \multirow[t]{4}{*}{1} & Jenis Kelamin Responden: & & \\
\hline & a. Pria & 70 & $64 \%$ \\
\hline & b. Wanita & 40 & $36 \%$ \\
\hline & Total & 110 & $100 \%$ \\
\hline \multirow[t]{6}{*}{2} & Usia Responden: & & \\
\hline & a. $<25$ Tahun & 30 & $27 \%$ \\
\hline & b. $26-35$ Tahun & 12 & $11 \%$ \\
\hline & c. $36-45$ Tahun & 7 & $6 \%$ \\
\hline & d. $>45$ Tahun & 61 & $56 \%$ \\
\hline & Total & 110 & $100 \%$ \\
\hline \multirow[t]{8}{*}{3} & Pendidikan Terakhir: & & \\
\hline & a. SD & 0 & - \\
\hline & b. SLTP & 2 & $2 \%$ \\
\hline & c. SLTA & 46 & $42 \%$ \\
\hline & d. Diploma & 23 & $21 \%$ \\
\hline & e. Sarjana & 38 & $34 \%$ \\
\hline & f. Magister & 1 & $1 \%$ \\
\hline & Total & 110 & $100 \%$ \\
\hline \multirow[t]{4}{*}{4} & Status Wajib Pajak: & & \\
\hline & a. Pribadi & 74 & $67 \%$ \\
\hline & b. Badan & 36 & $33 \%$ \\
\hline & Total & 110 & $100 \%$ \\
\hline \multirow[t]{5}{*}{5} & Kebijakan Pajak yang Diikuti: & & \\
\hline & a. Sunvet Policy & 0 & - \\
\hline & b. Tax Amnesty & 2 & $2 \%$ \\
\hline & c. Tidak Mengikuti & 108 & $98 \%$ \\
\hline & Total & 110 & $100 \%$ \\
\hline
\end{tabular}

Sumber : Data diolah (2017)

\section{Pengujian Instrumen}

\section{Uji Validitas}

Pengujian ini dilakukan dengan menguji korelasi antara skor setiap item dengan skor total masing-masing variabel melalui perbandingan antara nilai pearson correlation dengan $r$ tabel. Adapun nilai $r$ tabel untuk jumlah responden 110 dan $\alpha=0.05$ adalah sebesar 0,1874. Apabila $r_{\text {hitung }}>r_{\text {tabel }}$ maka kuesioner dikatakan valid dan sebaliknya. Hasil pengujian validitas menunjukkan seluruh item pertanyaan memiliki validitas di atas 0.1874 dengan traf signifikansi seluruh item pertanyaan mencapai 0.000 sehingga seluruhnya dapat dinyatakan lolos uji validitas atau valid.

\section{Uji Reliabilitas}

Uji reliabilitas dilakukan untuk melihat apakah instrumen (kuesioner) yang digunakan dapat dihandalkan dan tetap konsisten jika dilakukan pengulangan pada pengukuran. Pengujian ini dilakukan dengan membandingkan nilai Cronbach's Alpha terhadap judgement para ahli.
Hasil pengujian reliabilitas dari setiap pertayaan pada variabel sunset policy sebesar 0,780, tax amnesty sebesar 0,781, good governance sebesar 0,923 dan kepatuhan wp sebesar 0,886. Sehingga dapat ditarik kesimpulan bahwa instrumen berbentuk kuesioner yang digunakan reliabel dan memiliki kehandalan serta kekonsistenan apabila dilakukan pengukuran ulang, dimana dua variabel berpredikat dapat diterima (acceptable), satu variabel berpredikat sempurna (excellent), dan satu variabel lainnya bersifat baik (Good).

\section{Uji Asumsi Klasik \\ Uji Normalitas}

Uji ini digunakan untuk mengetahui normal atau tidaknya distribusi nilai residual dalam model regresi. Adapun metode dalam pengujian ini, yaitu metode statistika One Sample Kolmogorov Smirnov.

Hasil uji normalitas tersaji dalam Tabel 4 di bawah ini: 


\begin{tabular}{llr}
\hline & & Unstandardized Residual \\
\hline $\mathrm{N}$ & & 110 \\
Normal Parametersa,b & Mean &, 0000000 \\
& Std. Deviation & 2,68830825 \\
Most Extreme Differences & Absolute &, 118 \\
& Positive &, 098 \\
& Negative &,- 118 \\
Kolmogorov-Smirnov Z & & 1,237 \\
Asymp. Sig. (2-tailed) & &, 094 \\
\hline
\end{tabular}

a. Test distribution is Normal.

b. Calculated from data.

Sumber: Data Primer Diolah 2017

Berdasarkan tabel 4 terlihat bahwa nilai sigfinikansi (asymp.sig.) untuk uji 2 arah adalah sebesar 0,094 atau 0,094>0,05. Berdasarkan data di atas, dapat disimpulkan bahwa distribusi data normal terjadi dalam model regresi penelitian ini.

\section{Uji Multikolinearitas}

Uji multikolinearitas bertujuan untuk mendeteksi apakah terdapat penyimpangan berupa adanya hubungan yang bersifat linear Tabel 5: Hasil Uji Multikolinearitas dengan Metode VIF

\begin{tabular}{clrr}
\hline & \multirow{2}{*}{ Model } & \multicolumn{2}{c}{ Collinearity Statistics } \\
& & Tolerance & VIF \\
\hline 1 & Sunset Policy &, 622 & 1,608 \\
& Tax Amnesty &, 613 & 1,632 \\
& Good Governance &, 697 & 1,434 \\
\hline \multicolumn{2}{c}{ a. Dependent Variable: Kepatuhan Wajib Pajak }
\end{tabular}

Sumber: Data Primer Diolah (2017)

Berdasarkan Tabel 5 dapat diketahui bahwa ketiga variabel memiliki nilai Varian Inflation Factor yang masing-masing adalah variabel sunset policy sebesar 1,608, variabel Tabel 6: Hasil Uji Heterokesdastisitas (Uji Glejser) antar variable bebas dalam model regresi. Metode yang dilakukan adalah metode VIF (Varian Inflation Factor) dengan kriteria yang mensyaratkan nilai VIF harus kurang dari 10, yang berarti tidak terjadinya gejala multikolinerait.

Hasil uji multikolinerait dengan metode VIF pada penelitian ini tersaji dalam tabel 5 dibawah ini:

tax amnesty sebesar 1,632 dan variabel good governance sebesar 1,434. Ketiga variabel memiliki nilai $(\mathrm{VIF}<10)$, artinya tidak terjadi gejala multikolinearitas dalam model regresi.

\section{Uji Heteroskedastisitas}

Uji heteroskesdastisitas bertujuan untuk mendeteksi apakah terdapat gejala ketidaksamaan varian residual seluruh pengamatan pada model regresi. Pengujian ini dilakukan dengan metode Glejser, dimana hasil uji ini terdapat pada tabel 6 berikut:

Coefficients $^{\mathrm{a}}$

\begin{tabular}{|c|c|c|c|c|c|c|}
\hline \multirow{2}{*}{\multicolumn{2}{|c|}{ Model }} & \multicolumn{2}{|c|}{ Unstandardized Coefficients } & \multirow{2}{*}{$\begin{array}{c}\text { Standardized } \\
\text { Coefficient } \\
\text { Beta }\end{array}$} & \multirow[t]{2}{*}{$\mathrm{T}$} & \multirow[t]{2}{*}{ Sig. } \\
\hline & & B & Std. Error & & & \\
\hline \multirow[t]{4}{*}{1} & (Constant) & 1,818 & 1,796 & & 1,012 & ,314 \\
\hline & Sunset Policy &,- 136 & 108 &,- 152 & $-1,257$ & ,211 \\
\hline & Tax Amnesty & ,197 & 099 & ,240 & 1,977 & 051 \\
\hline & Good Governance &,- 035 & 040 &,- 100 &,- 873 & ,384 \\
\hline
\end{tabular}

a. Dependent Variable: ABS_RES

Sumber: Data Primer Diolah 2017

Berdasarkan Tabel 6 di atas, dapat dinyatakan bahwa tidak terjadi masalah heteroskedastisitas dalam model regresi karena ketiga variabel bebas memiliki nilai signifikansi diatas 0,05 .

\section{Uji Linearitas}

Uji Linieritas bertujuan untuk mengetahui apakah secara signifikan terdapat hubungan linear antara dua buah variabel. Berikut hasil uji linearitas pada Tabel 7:

Tabel 7: Hasil Uji Linearitas 


\begin{tabular}{lc}
\hline $\begin{array}{c}\text { Variabel } \\
\text { Independen }\end{array}$ & $\begin{array}{c}\text { Nilai Significancy of } \\
\text { Linearity }\end{array}$ \\
\hline Sunset Policy & 0,000 \\
Tax Amnesty & 0,000 \\
Good Governance & 0,000 \\
\hline Sumber: Data Primer Diolah (2017) \\
Berdasarkan Tabel 7 ketiga variabel \\
bebas secara individual memiliki nilai \\
signifikansi lineraitas (sig. of linearity) sebesar \\
0,000 dengan variable terikat kepatuhan wajib \\
pajak mempunyai nilai signifikansi lineraitas \\
(sig. of linearity) sebesar 0,00. Dengan \\
demikian karena nilai sig. of linearity lebih \\
kecil dari 0,05 (sig. of linearity < 0,05) maka \\
dapat disimpulkan seluruh variabel bebas \\
(sunset policy, tax amnesty dan good \\
governance) memiliki hubungan linear \\
terhadap variabel terikat.
\end{tabular}

\section{Analisis Regresi Linier Berganda}

Analisis ini dilakukan untuk mengetahui arah hubungan antara variabel independen dengan variabel dependen (positif atau negative) dan untuk memprediksi nilai dari variabel dependen apabila nilai variabel independen mengalami kenaikan atau penurunan yang disusun berdasarkan output SPSS. Adapun persamaan regresi linier berganda dalam penelitian ini adalah sebagai berikut.

$\mathrm{Y}=13,224+0,261 \mathrm{X}_{1}+0,124 \mathrm{X}_{2}+0,435 \mathrm{X}_{3}$

Dimana:

$\mathrm{Y}=$ Kepatuhan WP

$\mathrm{X}_{1}=$ Sunset Policy

$\mathrm{X}_{2}=$ Tax Amnesty

$\mathrm{X}_{3}=$ Good Governance

Interprestasi persamaan di atas dapat diuraikan sebagai berikut:

a. Konstanta sebesar 13,224 artinya jika sunset policy, tax amnesty, dan good governance bernilai 0 (nol) dan tidak mengalami perubahan, maka angka kepatuhan wajib pajak bernilai 13,224 tingkat.

b. Koefisien regresi variabel sunset policy sebesar 0,261 artinya apabila variabel independen lainnya bernilai konstan dan variabel sunset policy $\left(\mathrm{X}_{1}\right)$ mengalami kenaikan berjumlah satu satuan, maka besarnya nilai dari kepatuhan wajib pajak (Y) akan meningkat pula sebesar 0,261 tingkat. Koefisien bernilai positif mengindikasikan adanya hubungan yang searah antara sunset policy dengan kepatuhan WP.

c. Koefisien regresi variabel tax amnesty sebesar 0,124 artinya jika variabel independen lainnya bernilai konstan dan variabel tax amnesty $\left(\mathrm{X}_{2}\right)$ mengalami kenaikan sebesar satu satuan, maka nilai kepatuhan wajib pajak (Y) akan mengalami kenaikan sebesar 0,124 tingkat. Terjadinya hubungan searah antara variabel tax amnesty dan kepatuhan wp ditunjukkan dengan nilai koefisien yang bernilai positif.

d. Koefisien regresi variabel good governance sebesar 0,435 artinya jika variabel independen lainnya bernilai konstan dan variabel good governance $\left(\mathrm{X}_{3}\right)$ mengalami kenaikan sebesar satu satuan, maka kepatuhan wajib pajak (Y) akan mengalami kenaikan sebesar 0,435 tingkat. Koefisien bernilai positif menunjukkan terjadi hubungan yang searah antara variabel good governance dengan kepatuhan wp.

\section{Koefisien Korelasi}

Secara teknis, analisa ini menunjukkan sebesar apa hubungan antara variabel independen secara serentak terhadap variabel dependen dengan nilai $\mathrm{R}$ pada tabel 8 berikut. 
Tabel 8: Hasil Analisis Korelasi Berganda

Model Summaryb

\begin{tabular}{ccccc}
\hline Model & $R$ & R Square & Adjusted R Square & $\begin{array}{c}\text { Std. Error of the } \\
\text { Estimate }\end{array}$ \\
\hline 1 &, $727^{\mathrm{a}}$ &, 528 &, 515 & 2,72608 \\
\hline
\end{tabular}

a. Predictors: (Constant), X3, X1, X2

b. Dependent Variable: $Y$

Sumber: Data Primer Diolah (2017)

Berdasarkan tabel 8 diperoleh angka $\mathrm{R}$ sebesar 0,727 yang berarti menujukkan tingkat hubungan yang "kuat" antara variabel $\mathrm{X}$ (independen) dengan variabel $\mathrm{Y}$ (dependen).

\section{Koefisien Determinasi}

Koefisien ini menunjukan seberapa besar prosentase variasi variabel independen yang digunakan dalam model mampu menjelaskan variasi variabel dependen dengan melihat nilai R square.

Berdasarkan tabel 8 di atas angka $\mathrm{R}$ square bernilai 0,528 berarti $52,8 \%$ variasi dari kepatuhan WP dapat dijelaskan oleh variasi dari ketiga variabel independen, sedangkan sisanya $(100 \%-52,8 \%=47,2 \%)$ dijelaskan oleh sebab-sebab lain atau dijelaskan oleh variabel lain yang tidak dimasukkan dalam model penelitian ini.

\section{Pengujian Hipotesis}

Uji F

Uji F digunakan untuk mengetahui pengaruh variabel independen (sunset policy, tax amnesty, dan good governance) secara simultan terhadap variabel dependen (kepatuhan wajib pajak). Hasil output analisa regresi menunjukkan bahwa nilai $\mathrm{F}$ seperti pada tabel 9 di bawah ini.

Tabel 9: Hasil Uji F (Uji Simultan)

\begin{tabular}{|c|c|c|c|c|c|c|}
\hline \multicolumn{2}{|c|}{ Model Regression } & $\begin{array}{l}\text { Sum of } \\
\text { Squares }\end{array}$ & $\mathrm{df}$ & Mean Square & $\mathrm{F}$ & Sig. \\
\hline \multirow{3}{*}{1} & & 882,257 & 3 & 294,086 & 39,573 &, $000^{\mathrm{b}}$ \\
\hline & Residual & 787,743 & 106 & 7,432 & & \\
\hline & Total & 1670,000 & 109 & & & \\
\hline
\end{tabular}

a. Dependent Variable: kepatuhan wajib pajak

b. Predictors: (Constant), Sunset Policy, Tax Amnesty, Good Governance Sumber: Data Primer Diolah (2017)

Dari output uji ANOVA terlihat $\mathrm{F}_{\text {hitung }}$ sebesar 39,573> $\mathrm{F}_{\text {tabel }}$ sebesar 2,690303 dengan probabilitas signifikan sebesar 0,000 dapat ditarik kesimpulan bahwa terdapat pengaruh secara signifikan antara sunset policy, tax amnesty, dan good governance secara simultan terhadap kepatuhan WP, atau dapat dikatakan bahwa $\mathbf{H}_{\mathbf{a}}$ diterima dan $\mathbf{H}_{\mathbf{0}}$ ditolak.

\section{Uji t (Parsial)}

Uji ini digunakan untuk menguji apakah variabel independen (sunset policy, tax amnesty, dan good governance) secara parsial berpengaruh signifikan terhadap variabel dependen (kepatuhan wajib pajak) dengan membandingkan besarnya nilai $r_{\text {tabel }}$ terhadap nilai $r_{\text {hitung }}$ dari masing-masing variabel.

Nilai $r_{\text {tabel }}$ diperoleh dengan menggunakan tingkat keyakinan 95\% ( $\mathrm{a}=5 \%)$ serta derajat kebebasan (df) $n-k-1$ atau 1103-1= 106 (n adalah jumlah responden dan $\mathrm{k}$ adalah jumlah variabel independen) sehingga hasil diperoleh untuk $t_{\text {tabel }}$ sebesar 1,982597. Hasil analisis regresi ditunjukan dalam Tabel 10 berikut: 
Tabel 10: Hasil Uji t (Uji Parsial)

\section{Coefficients ${ }^{\mathrm{a}}$}

\begin{tabular}{|c|c|c|c|c|c|}
\hline \multirow[b]{2}{*}{ Model } & \multicolumn{2}{|c|}{$\begin{array}{l}\text { Unstandardized } \\
\text { Coefficients }\end{array}$} & \multirow{2}{*}{$\begin{array}{c}\text { Standardized } \\
\text { Coefficients } \\
\text { Beta } \\
\end{array}$} & \multirow[b]{2}{*}{$\mathrm{T}$} & \multirow[b]{2}{*}{ Sig. } \\
\hline & B & Std. Error & & & \\
\hline 1 (Constant) & 13,224 & 2,590 & & 5,106 & ,000 \\
\hline Sunset Policy & 261 & 156 & 142 & 1,676 & ,097 \\
\hline Tax Amnesty & ,124 & 143 & ,074 & ,865 & 389 \\
\hline Good Governance & ,435 & ,058 & 604 & 7,557 & ,000 \\
\hline
\end{tabular}

a. Dependent Variable: Kepatuhan Wajib Pajak

Sumber : Data Primer Diolah (2017)

\section{Varibel Sunset Policy}

Berdasarkan hasil pengujian ANOVA, variabel sunset policy memiliki nilai $t_{\text {hitung }}$ sebesar 1,676 $<t_{\text {tabel }}$ sebesar 1,982597 dengan probabilitas signifikan senilai 0,097. Dapat disimpulkan bahwa sunset policy tidak berpengaruh terhadap kepatuhan wajib pajak.

Temuan ini sejalan dengan penelitian yang dilakukan oleh Permatasari (2016) dengan hasil penelitian yang menyatakan bahwa sunset policy jilid II tidak berpengaruh pada kepatuhan wajib pajak. Hal tersebut diakibatkan oleh minimnya pengetahuan wajib pajak mengenai perpajakan serta kurang maksimalnya intensitas serta kualitas dari sosialisasi kebijakan sehingga jumlah peserta yang mengikuti kebijakan sunset policy ini masih sangat minim.

\section{Variabel Tax Amnesty}

Menurut output SPSS yang tertera pada tabel 10, variabel tax amnesty memiliki thitung sebesar 0,865 $<t_{\text {tabel }}$ sebesar 1,982597 dengan probabilitas signifikan sebesar 0,389. Maka, variabel tax amnesty tidak berpengaruh terhadap kepatuhan wajib pajak.

Hal ini tidak sesuai dengan penelitian dari Ngadiman \& Huslin (2015) dimana hasil penelitian menyatakan bahwa tax amnesty berpengaruh positif terhadap tingkat kepatuhan wajib pajak. Hal ini disebabkan oleh minimnya frekuensi sosialisasi yang dilakukan pihak Kantor Pelayanan Pajak mengenai kebijakan tax amnesty.

\section{Varibel Good Governance}

Berdasarkan hasil uji ANOVA pada tabel 10, variabel good governance memiliki thitung sebesar 7,557 $>t_{\text {tabel }}$ sebesar 1,982597 dengan probabilitas signifikan sebesar 0,000. Kesimpulannya bahwa good governance berpengaruh positif terhadap kepatuhan wajib pajak.

Temuan ini sejalan dengan hasil penelitian dari Gunadi (2013) yakni adanya pengaruh penerapan good governance dalam pelayanan pajak terhadap kepatuhan WP. Hal ini sesuai dengan persepsi dari wajib pajak selaku responden bahwa semakin baik pelayanan pajak dari pihak kantor pelayanan pajak, membuat wajib pajak semakin nyaman untuk bertransaksi serta memenuhi kewajiban perpajakannya sehingga akan meningkatkan kepatuhan dari wajib pajak itu sendiri.

\section{KESIMPULAN}

1. Sunset policy, tax amnesty, dan good governance secara simultan berpengaruh terhadap kepatuhan wajib pajak yang terdaftar di Kantor Pelayanan Pajak Pratama Majalaya. Artinya, semakin efektif kedua kebijakan tersebut (sunset policy dan tax amnesty) yang didukung dengan semakin baiknya penerapan good governance dalam pelayanan pajak maka semakin tinggi pula tingkat kepatuhan wajib pajak.

2. Secara parsial variabel sunset policy tidak berpengaruh terhadap kepatuhan wajib pajak yang terdaftar di Kantor Pelayanan Pajak Pratama Majalaya.

3. Secara parsial variabel tax amnesty tidak berpengaruh terhadap kepatuhan wajib pajak yang terdaftar di Kantor Pelayanan Pajak Pratama Majalaya.

4. Secara parsial variabel good governance berpengaruh positif dan signifikan terhadap kepatuhan wajib pajak yang terdaftar di Kantor Pelayanan Pajak Pratama Majalaya. Berpengaruhnya good governance berarti semakin baik penerapan good governance dalam pelayanan pajak dari pihak kantor 
pelayanan pajak dapat memicu meningkatnya kepatuhan wajib pajak. Adapun bentuk good governance dalam pelayanan pajak itu sendiri terdiri dari akuntabilitas, efisiensi dan efektivitas, responsivitas, keadilan, partisipasi, dan transparansi.

\section{DAFTAR PUSTAKA}

Andreas, dan Enni Savitri, 2015, The Effect of Tax Socialization, Tax Knowledge, Expediency of Tax ID Number and Service Quality on Taxpayers Compliance with Tax Payers Awareness As Mediating Variables, Procedia Social and Behavioral Science, 211, 163-168.

Bayer, R. C., Oberhofer, H., dan Winner, H., 2014, The Occurrence of Tax Amnesties: Theory and Evidence, Journal of Public Economics(125), 7082.

Damayanti, T. W., Sutrisno, Subekti, I., dan Baridwan, Z., 2015, Trust and Uncertainly Orientation: An Efforts to Create Tax Compliance in Social Psychology Framework, Procedia Social and Behavioral Sciences(211), 938-944.

Dwiyanto, Agus, 2005, Mewujudkan Good Governance Melalui Publik, Yogyakarta: Gadjah Mada University Press.

Fatmawati, 2015, Pengaruh Pemahaman Wajib Pajak Atas PP No. 46 Tahun 2013 dan Implementasi Self Assessment System Terhadap Kepatuhan Wajib Pajak dengan Persepsi Wajib Pajak sebagai Variabel Moderasi (Studi Empiris Pada Pelaku UMKM Kerajinan Gerabah Kasongan), Skripsi Sarjana, Program Studi Akuntansi Jurusan Pendidikan Akuntansi Fakultas Ekonomi, Universitas Negeri Yogyakarta.

Gunadi, Boris S. K., 2013, Pengaruh Penerapan Good Governance dalam Pelayanan Pajak Terhadap Kepatuhan Wajib Pajak Pada Kantor Pelayanan Pajak Pratama Cakung Dua, Skripsi Sarjana, Fakultas Ilmu
Sosial dan Ilmu Politik, Universitas Indonesia.

Hutagaol, J., Darusalam, dan Septriadi, D., 2007, Kapita Selekta Perpajakan, Jakarta: Salemba Empat.

Indriantoro, N., dan Supomo, B., 2002, Metodologi Penelitian Bisnis, Yogyakarta: Penerbit BPFE.

Istiqomah, 2016, Analisis Kepatuhan Wajib Pajak Orang Pribadi Berkaitan dengan Adanya Kebijakan Penghapusan Sanksi Pajak pada Kantor Pelayanan Pajak Pratama Bantul, Skripsi Sarjana, Fakultas Ekonomi Universitas Negeri Yogyakarta, Yogyakarta.

Malhotra, N.K, 2004, Riset Pemasaran, Pendekatan Terapan, Edisi Bahasa Indonesia, Jakarta: PT. Indeks Kelompok Gramedia.

Mardiasmo, 2009, Akuntansi Sektor Publik, Yogyakarta: Andi.

Moh. Zain, 2004, Manajemen Perpajakan,

Jakarta: Salemba Empat.

Munawaroh, S, Haris W., Intan I., 2014, FaktorFaktor yang Mempengaruhi Kemauan untuk Membayar Pajak Wajib Pajak Orang Pribadi yang Melakukan Pekerjaan Bebas (Studi Pada KPP Pratama Kota Madiun), Jurnal Penelitian, Fakultas Ekonomi Universitas Katolik Widya Mandala, Madiun.

Narimawati, Umi, 2010, Penulisan Karya Ilmiah, Jakarta: Penerbit Genesis.

Nasucha, Chaizi, 2004, Reformasi Administrasi Publik: Teori dan Aplikasi, Jakarta: Gramedia.

Ngadiman dan Daniel Huslin, 2015, Pengaruh Sunset Policy, Tax Amnesty, dan Sanksi Pajak Terhadap Kepatuhan Wajib Pajak (Studi Empiris di Kantor Pelayanan Pajak Pratama Jakarta Kembangan), Jurnal Akuntansi, Fakultas Ekonomi Universitas Tarumanagara, Jakarta.

Pandiangan, Liberti, 2014, Administrasi Perpajakan, Jakarta: Erlangga

Peraturan Menteri Keuangan Republik Indonesia Nomor 91/PMK.03/2015 Tentang Pengurangan atau Penghapusan Sanksi Administrasi atas Keterlambatan Penyampaian Surat Pemberitahuan, Pembetulan Surat 
Pemberitahuan, dan Keterlambatan Pembayaran atau Penyetoran Pajak.

Permatasari, Anisah R., 2016, Pengaruh Kebijatak Sunset Policy Jilid II Terhadap Kepatuhan Wajib Pajak (Studi Kasus Pada Kantor Pelayanan Pajak Bojonagara), Jurnal Penelitian, Fakultas Ekonomi Universitas Kristen Maranatha, Bandung.

Priyatno, Duwi, 2012, Cara Kilat Belajar Analisis Data dengan SPSS 20, Edisi I, Yogyakarta: Penerbit ANDI.

Resmi, Siti, 2014, Perpajakan Teori dan Kasus, Buku 1 Edisi 8, Jakarta: Salemba Empat.

Samira, Leni, 2014, Pengaruh Kesadaran Wajib Pajak, Pelayanan Fiskus dan Sanksi Pajak Terhadap Kepatuhan Wajib Pajak Pada KPP Pratama Kota Bogor, Skripsi Sarjana, Fakultas Ekonomi Universitas Djuanda, Bogor.

Soedibjo, Bambang S., 2004, Pengantar Metode Penelitian, Edisi Revisi, Jurusan Sekolah Tinggi Ilmu Ekonomi, Bandung.

Sugiyono, 2016, Metode Penelitian Kuantitatif, Kualitatif, dan R\&D, Cetakan ke-23, Bandung: Penerbit ALFABETA.

Surat Edaran Direktur Jenderal Pajak Nomor: SE-08/PJ/2014 Tentang Target Rasio Kepatuhan Penyampaian Surat Pemberitahuan Tahunan PPh Pada Tahun 2014.

Umar, Husein, 2005, Metode Penelitian Untuk Skripsi dan Tesis Bisnis, Jakarta: PT. Raja Grafindo Persada.

Undang-Undang Republik Indonesia Nomor 11 Tahun 2016 Tentang Pengampunan Pajak.

Undang-Undang Republik Indonesia Nomor 16 Tahun 2009 Tentang Penetapan Peraturan Pemerintah Pengganti Undang-Undang Nomor 5 Tahun 2008 Tentang Perubahan Keempat Atas
Undang-Undang Nomor 6 tahun 1983 Tentang Ketentuan Umum dan Tata Cara Perpajakan Menjadi UndangUndang.

Undang-Undang Republik Indonesia Nomor 28 Tahun 2007 Tentang Ketentuan Umum dan Tata Cara Perpajakan.

Yustinus, Prastowo, 2011, Panduan Lengkap Pajak, Jakarta: Raih Asa Sukses.

http://www.kemenkeu.go.id/sites/default/file s/Analisis\%20Implementasi\%20Tax $\%$ 20Amnesty\%20di\%20Indonesia.pdf (diakses November 2016)

http://bisnis.liputan6.com/read/2217599/me ngupas-sunset-policy-amp-taxamnesty-senjata-kejar-target-pajak (diakses November 2016)

https://web.facebook.com/permalink.php?sto ry fbid $=10152858475463403 \& i d=511$ $10098402 \&$ substory index $=0 \& \mathrm{rdr}$ (diakses Februari 2017)

https://www.bps.go.id/index.php/brs/1268 (diakses Maret 2017)

http://www.kemenkeu.go.id/apbn2016 (diakses Maret 2017)

http://economy.okezone.com/read/2015/03/ 23/20/1122994/penerimaan-pajaklima-tahun-terakhir-tak-capai-target (diakses Maret 2017)

http://finansial.bisnis.com/read/20160107/1 0/507661/tax-ratio-amblas-ke-titikterendah-sejak-2010 (diakses Maret 2017)

http://www.cnnindonesia.com/ekonomi/201 70101110231-78-183447/periode-iitax-amnesty-berakhir-dengan-uangtebusan-mini/ (diakses Maret 2017)

https://csuryana.wordpress.com/2010/03/25 /data-dan-jenis-data-penelitian/ (diakses Maret 2017)

https://m.tempo.co/read/news/2017/04/18/ 087867110/djp-sebut-baru-58-97persen-wajib-pajak-lapor-spt (diakses Agustus 2017) 